\title{
Female-Specific Intergenerational Transmission Patterns of the Human Corticolimbic Circuitry
}

\author{
Bun Yamagata, ${ }^{1,2,3}$ Kou Murayama,,${ }^{4,5}$ Jessica M. Black, ${ }^{6}$ Roeland Hancock, ${ }^{7}$ Masaru Mimura, ${ }^{2}$ Tony T. Yang, ${ }^{7}$ \\ Allan L. Reiss, ${ }^{1}$ and $\odot$ Fumiko Hoeft ${ }^{2,7}$ \\ ${ }^{1}$ Center for Interdisciplinary Brain Sciences Research, Department of Psychiatry and Behavioral Sciences, Stanford University School of Medicine, Stanford, \\ California 94305, ${ }^{2}$ Department of Neuropsychiatry, Keio University School of Medicine, Tokyo 160-8582, Japan, ${ }^{3}$ Department of Neuropsychiatry, Showa \\ University School of Medicine, Tokyo 157-8577, Japan, ${ }^{4}$ Department of Psychology, University of Reading, Whiteknights, Reading RG6 6AL, United \\ Kingdom, ${ }^{5}$ Research Unit of Psychology, Education, and Technology, Kochi University of Technology, Kochi 782-8502, Japan, ${ }^{6}$ Graduate School of Social \\ Work, Boston College, Chestnut Hill, Massachusetts 02467, and 'Division of Child and Adolescent Psychiatry, Department of Psychiatry, University of \\ California San Francisco, San Francisco, California 94143
}

Parents have large genetic and environmental influences on offspring's cognition, behavior, and brain. These intergenerational effects are observed in mood disorders, with particularly robust association in depression between mothers and daughters. No studies have thus far examined the neural bases of these intergenerational effects in humans. Corticolimbic circuitry is known to be highly relevant in a wide range of processes, including mood regulation and depression. These findings suggest that corticolimbic circuitry may also show matrilineal transmission patterns. Therefore, we examined human parent- offspring association in this neurocircuitry and investigated the degree of association in gray matter volume between parent and offspring. We used voxelwise correlation analysis in a total of 35 healthy families, consisting of parents and their biological offspring. We found positive associations of regional gray matter volume in the corticolimbic circuit, including the amygdala, hippocampus, anterior cingulate cortex, and ventromedial prefrontal cortex between biological mothers and daughters. This association was significantly greater than mother-son, father- daughter, and father-son associations. The current study suggests that the corticolimbic circuitry, which has been implicated in mood regulation, shows a matrilinealspecific transmission patterns. Our preliminary findings are consistent with what has been found behaviorally in depression and may have clinical implications for disorders known to have dysfunction in mood regulation such as depression. Studies such as ours will likely bridge animal work examining gene expression in the brains and clinical symptom-based observations and provide promising ways to investigate intergenerational transmission patterns in the human brain.

Key words: anxiety disorder; MRI; intergenerational imaging

\section{Significance Statement}

Parents have large genetic and environmental influences on the offspring, known as intergenerational effects. Specifically, depression has been shown to exhibit strong matrilineal transmission patterns. Although intergenerational transmission patterns in the human brain are virtually unknown, this would suggest that the corticolimbic circuitry relevant to a wide range of processes including mood regulation may also show matrilineal transmission patterns. Therefore, we examined the degree of association in corticolimbic gray matter volume (GMV) between parent and offspring in 35 healthy families. We found that positive correlations in maternal corticolimbic GMV with daughters were significantly greater than other parent- offspring dyads. Our findings provide new insight into the potential neuroanatomical basis of circuit-based female-specific intergenerational transmission patterns in depression.

\section{Introduction}

Parents have large genetic and environmental influences on offspring's cognition, behavior, and brain (Curley and Mashoodh,
2010; Cabrera et al., 2011; Curley, 2011). Furthermore, intergenerational trait transmission is often observed in the psychopathology of major psychiatric conditions, such as mood disorders 
(Curley and Mashoodh, 2010; Guilmatre and Sharp, 2012). For example, offspring of depressed parents are two to three times more likely than the offspring of nondepressed controls to exhibit elevated levels of depression (Weissman et al., 2006). If so, the neurocircuitry involved in depression may also show intergenerational transmission effects. A large body of human neuroimaging studies indicate that corticolimbic circuitry, which includes the amygdala, hippocampus, anterior cingulate cortex (ACC), and ventromedial prefrontal cortex [vmPFC-orbitofrontal cortex (OFC) and gyrus rectus], is central in mood disorders (Price and Drevets, 2010). Growing animal and human neuroimaging literature has similarly implicated this corticolimbic circuitry as the biological substrate of emotion regulation (Banks et al., 2007). This points to corticolimbic circuitry as an important target for investigating depression and its intergenerational effects.

In depression, a maternal transmission pattern is observed, where maternal depression is associated with numerous adverse outcomes among offspring (Downey and Coyne, 1990; Beardslee et al., 1998), particularly between depression amongst mothers and adolescent daughters (Davies and Windle, 1997; Goodman and Gotlib, 1999; Goodman, 2007; Thompson et al., 2014). More specifically, maternal depressive symptoms are correlated with that of daughters $(r=0.44)$ but not sons $(r=-0.01$; Fergusson et al., 1995), as well as maternal depressive/anxiety disorder correlating with daughters' but not sons' internalizing symptoms (Piche et al., 2011). Accordingly, we would expect that there is a female-specific neurobiological transmission pattern in the corticolimbic circuitry. Additionally, in the animal literature, maternal gestational stress significantly decreased the number of hippocampal neurons as a result of increases in calcium content and oxidant generation in the hippocampal CA3 region in female offspring but not in male offspring. Females may have a higher generation of oxidants because of higher corticosterone caused by prenatal stress (Zhu et al., 2004). Moreover, the hypothalamus-pituitary-adrenal (HPA) axis responses to gestational stress are different between male and female offspring. Basal and stressinduced increases in corticosterone levels are found only in prenatally stressed female offspring (Weinstock $\mathrm{M}$ et al., 1992; Szuran et al., 2000). Such female-dominant HPA axis activity may be caused by a greater transport of corticosterone from maternal blood across the placenta of female fetuses than of male fetuses (Montano et al., 1993). These animal studies have revealed the underlying neurobiological underpinnings of female-specific intergenerational effects. However, to date, there have been no neuroimaging studies that examined the neural evidence of intergenerational transmission patterns in humans. Studies such as these can contribute unique information that can bridge animal research and human clinical studies that is different from the more common approach, i.e., to examine heritability in twins, in which sex-specific intergenerational transmission patterns cannot be assessed (Alemany et al., 2013).

Nordahl, University of California Davis MIND Institute, Sacramento, CA) and R01MH103371 (principle investigator: D. Amaral, University of California Davis MIND Institute), National Science Foundation Grant NSF1540854 SL-CN (principle investigator: A. Gazzaley), the UCSF Dyslexia Center, the UCSF Academic Senate Award, a UCSF-Center for Childhood (reativity Neuroscience Fellowship (and Liebe Patterson), and the Dennis and Shannon Wong DSEA ' 88 Family Foundation. K.M. was supported in part by the Marie Curie Career Integration Grant (CIG630680) and JSPS KAKENHI 15H05401. T.T.Y. was supported in part by NIMH Grants 7R01MH085734, 3R01MH085734-02S1, and R01MH085734-05S1.

The authors declare no competing financial interests.

Correspondence should be addressed to Dr. Fumiko Hoeft, Division of Child and Adolescent Psychiatry, Department of Psychiatry, University of California San Francisco, San Francisco, CA 94143-0984. E-mail: fumiko.hoeft@ucsf.edu.

DOI:10.1523/JNEUROSCI.4974-14.2016

Copyright (C) 2016 the authors $\quad 0270-6474 / 16 / 361255-07 \$ 15.00 / 0$
The purpose of the current study was to examine femalespecific intergenerational transmission patterns on brain structure in parent-offspring pairs in healthy individuals. We hypothesized that mother-daughter pairs would reveal significantly positive gray matter volume (GMV) associations in the corticolimbic brain regions (implicated in mood disorders) compared with other parent-offspring pairs. Our hypothesis was based on findings from previous studies demonstrating that depression exhibits strong female-specific intergenerational transmission patterns indicated above (Fergusson et al., 1995; Goodman and Gotlib, 1999; Goodman, 2007; Piche et al., 2011). Therefore, we focused on corticolimbic circuitry, including the amygdala, hippocampus, ACC, and vmPFC GMV, and analyzed the degree of association between mothers and daughters compared with mothers and sons, fathers and sons, and fathers and daughters, in these brain regions.

\section{Materials and Methods}

Participants. A total of 35 healthy families, consisting of parents aged 33-48 years and their biological offspring aged 5-13 years, were included for the present study from a larger study that was not focused on the corticolimbic system and related behavior. Participants were recruited from local newspapers, school mailings, flyers, and mother's clubs. Exclusion criteria for this study were the presence of neurological or psychiatric disorders, including substance abuse, the use of medication, and/or contraindication to MRI (e.g., metal in the subject's body), in either parent or offspring reported by the parents. However, it is still possible that mothers omitted reporting past or current use of steroids, including contraceptives, that may affect brain morphometry (Pletzer et al., 2010), because these are commonly taken among healthy people. The Stanford University and University of California San Francisco Panel on Human Subjects in Medical Research approved the study. After complete description of the study to the participants, written informed consent and assent were obtained from parents and children, respectively. Thirtyone families had one child and four families had two children. We created four parent-offspring subgroups, including 16 mother-daughter, 18 mother-son, 15 father-daughter, and 18 father-son pairs.

Demographic, cognitive, and behavioral assessments. Behavioral data (such as mental health status) of offspring were obtained by the Behavioral Assessment System for Children, Second Edition (BASC-2; Reynolds and Kamphaus, 2004), which is a multimethod, multidimensional system used to evaluate the adaptive and problematic behavior of children and young adults aged 2-25 years. We collected parent-rating scales (PRS) of nine clinical scales, including aggression, anxiety, attention problems, atypicality, conduct problems, depression, hyperactivity, somatization, and withdrawal, and five adaptive scales, including activities of daily living, adaptability, functional communication, leadership, and social skills. The BASC-2 was normed in the United States using a large representative sample of youth (including $>13,000$ cases) from across the nation. Aged-normed $T$ scores are continuously distributed within the population, with a mean of 50 and an SD of 10. A high score implies more emotional and behavioral problems, except for the adaptive skills scale for which a high score implies more attributes that contribute to healthy functioning. More specifically, on the clinical scales, $T$ scores from 60 to 69 indicate "at-risk" behaviors and 70 and above indicate "clinically significant" concerns. Conversely, analogous cutoffs are established for the adaptive skills scale whereby $T$ scores from 31 to 40 are considered to be at-risk and 30 or less are considered to be clinically significant.

To evaluate potential sex differences in age in our samples, we used independent Student's $t$ tests for age in parents and offspring, respectively. Because the BASC-2 PRS consists of 14 subscales, we performed a multivariate analysis of covariance (MANCOVA) to compare group differences between male and female offspring using these BASC-2 PRS subscales as dependent variables. Then, if a main effect of group on the MANCOVA was confirmed, a post hoc ANCOVA was performed. Although there were no significant differences in age, age was included as 
Table 1. Characteristics of parents and offspring

\begin{tabular}{|c|c|c|c|c|c|c|c|c|}
\hline \multirow[b]{2}{*}{ Characteristic } & \multicolumn{4}{|l|}{ Parent } & \multicolumn{4}{|l|}{ Offspring } \\
\hline & Mother & Father & $T$ & $p$ & Daughter & Son & $T$ & $p$ \\
\hline$n$ & 30 & 29 & & & 19 & 20 & & \\
\hline Age & $41.3 \pm 3.4$ & $42.4 \pm 4.6$ & -0.76 & 0.45 & $8.9 \pm 1.3$ & $8.0 \pm 2.3$ & 1.36 & 0.19 \\
\hline BASC-2 PRS subscales (Tscore) & & & & & $(n=10)$ & $(n=10)$ & & 0.13 \\
\hline Hyperactivity & & & & & $51.4 \pm 8.3$ & $49.8 \pm 8.5$ & & \\
\hline Aggression & & & & & $51.5 \pm 8.8$ & $56.9 \pm 10.7$ & & \\
\hline Conduct problems & & & & & $50.0 \pm 6.9$ & $53.8 \pm 4.9$ & & \\
\hline Anxiety & & & & & $51.5 \pm 9.3$ & $53.3 \pm 11.1$ & & \\
\hline Depression & & & & & $50.9 \pm 8.4$ & $46.9 \pm 19.1$ & & \\
\hline Somatization & & & & & $56.8 \pm 14.2$ & $49.0 \pm 11.7$ & & \\
\hline Atypicality & & & & & $51.2 \pm 9.7$ & $50.9 \pm 11.4$ & & \\
\hline Withdrawal & & & & & $52.1 \pm 9.9$ & $61.3 \pm 13.2$ & & \\
\hline Attention problems & & & & & $48.8 \pm 7.9$ & $51.9 \pm 9.1$ & & \\
\hline Adaptability & & & & & $51.5 \pm 8.5$ & $43.4 \pm 7.3$ & & \\
\hline Social skills & & & & & $54.5 \pm 7.9$ & $42.5 \pm 7.3$ & & \\
\hline Leadership & & & & & $54.5 \pm 8.3$ & $49.6 \pm 5.1$ & & \\
\hline Activities of daily living & & & & & $51.0 \pm 7.7$ & $44.3 \pm 5.3$ & & \\
\hline Functional communication & & & & & $51.5 \pm 8.7$ & $49.3 \pm 7.5$ & & \\
\hline
\end{tabular}

The table presents means \pm SDs in age and standardized $T$ scores for all BASC-2 PRS subscales. In the BASC-2 PRS subscales, a MANCOVA controlling for age demonstrated no significant sex difference for T scores (Wilks' Lambda $=0.079$, $\left.F_{(14,4)}=3.33, p=0.13\right)$

covariate in the analyses because of the relatively wide range in age of the children (age range, 5-13 years). Because all data were originally collected for the purpose of a study examining the neural bases of academic achievement in the offspring, there were no relevant behavioral data in parents (except for measures such as IQ).

Image acquisition and preprocessing. MR images were acquired using a 3 T whole-body GE-Signa HDxt scanner (GE Healthcare) with a quadrature head coil at the Lucas Center for Imaging at Stanford University. For voxelbased morphometry (VBM), high-resolution T1 anatomical scans were obtained using a fast spoiled gradient recalled echo pulse sequence ( 160 coronal slices; TR, $8.5 \mathrm{~ms}$; TE, $1.7 \mathrm{~ms}$; inversion time, $300 \mathrm{~ms}$; flip angle, $15^{\circ}$; number of excitations, 1; FOV, $22 \mathrm{~cm}$; matrix, $256 \times 256$; thickness, $1.2 \mathrm{~mm}$; acquisition time, $4 \mathrm{~min} 34 \mathrm{~s}$ ). Images were first checked visually for scanner artifacts and anatomical anomalies. Preprocessing was done using DARTEL (Ashburner, 2007) for VBM in SPM8 (http://www.fil.ion.ucl.ac.uk/spm). We further selected the modulated normalized nonlinear-only option, which results in an analysis of relative differences in regional GMV, corrected for individual brain size. This allows comparing the absolute amount of tissue corrected for individual brain sizes.

Parent-offspring correlation in corticolimbic circuitry. First, we performed voxelwise correlation analysis of volumes between mother and daughter, controlling for daughter's age and limiting the analysis to the region of interest (ROI) using the BPM (Biological Parametric Mapping) toolbox (Casanova et al., 2007). We created one corticolimbic ROI, including bilateral amygdala, ACC, vmPFC including the OFC and gyrus rectus, hippocampus, and parahippocampus gyrus defined by Automated Talairach Atlas Label (Lancaster et al., 2000) in the Wake Forest University PickAtlas toolbox (http://fmri.wfubmc.edu/cms/software\#PickAtlas). ROI analyses were performed using a statistical threshold of $p=0.05$ for voxel height, which then was thresholded at a cluster threshold of $p=0.05$ for familywise error (FWE). This resulted in a brain map showing significant positive GMV correlations between mother and daughter.

Second, because our primary goal was to examine the specificity of the parent-offspring GMV relationship, the next steps were to create brain maps that compared correlation coefficients $(r)$ between different parent-offspring groups on a voxelwise basis in the corticolimbic ROI. Based on our a priori hypothesis, we generated three brain maps: (1) correlation coefficients (association) that were significantly stronger between mother-daughter compared with mother-son pairs to examine whether mothers show stronger effects on daughters than sons; (2) mother-daughter greater than father-daughter association to examine whether mothers compared with fathers show stronger effects on daughters; and (3) mother-daughter greater than father-son association to show, to the extent possible, sex-specific effects. One challenge in testing for statistical differences between correlations in our data is the partial dependency of the sample. For example, when we compare motherdaughter correlation with mother-son correlation, some observations are dependent (e.g., a mother who has a daughter and a son), but some others are not (e.g., a mother who has a daughter only). To address this statistical issue, we used a bootstrapping method (Efron and Tibshirani, 1993) to assess the significance of the difference between the two correlation coefficients. Specifically, we derived the SEs of the differences in correlations (e.g., SE of the differences in mother-daughter correlation and mother-son correlation) by repeatedly resampling the observed data. Importantly, the resampling procedure takes into account the (partial) dependency of the data, making it possible to precisely compute the SEs. Before implementing bootstrapping, each individual's processed voxelwise GMV values within the corticolimbic ROI were extracted and converted to matrices using an in-house MATLAB-based multivariate pattern analysis toolbox (Hoeft et al., 2008, 2011). We then ran bootstrapping with an in-house $R$ code ( $R$ Core Team, 2015). As a result, we obtained three brain maps representing significantly greater positive GMV correlation in mother-daughter pairs $(p<0.05)$ compared with mother-son, father-daughter, and father-son pairs, respectively. Finally, we overlapped these three brain maps and the FWE-corrected mother-daughter correlation map to identify the voxels that showed significantly greater positive correlations between mother-daughter pairs than for the other three pairings.

Correlation between regional brain volume and behavioral data. To examine whether the degree of GMV in brain regions that show significant positive association between mothers and daughters is associated with emotional and behavioral functioning in daughters, Pearson's correlation analyses were performed between GMV data and standardized scores from all BASC-2 scales obtained from the daughters. Based on previous behavioral reports showing female-specific transmission patterns in depression (Davies and Windle, 1997; Goodman and Gotlib, 1999; Goodman, 2007; Thompson et al., 2014), we hypothesized that there may be associations between daughters' GMV and their BASC-2 depression subscales. GMV data were extracted from clusters in the amygdala, ACC, OFC, gyrus rectus, and hippocampus that showed significant positive associations between mothers and daughters compared with other parent-offspring dyads within the corticolimbic ROI. All behavioral data were originally collected for the purpose of a different study, and hence we only had data from 10 of 16 daughters, making these results tentative and exploratory at best.

\section{Results}

Corticolimbic ROI analysis

In offspring, a MANCOVA showed no significant sex differences for $T$ scores in the BASC-2 PRS scales (Wilks' Lambda $=0.08$, 


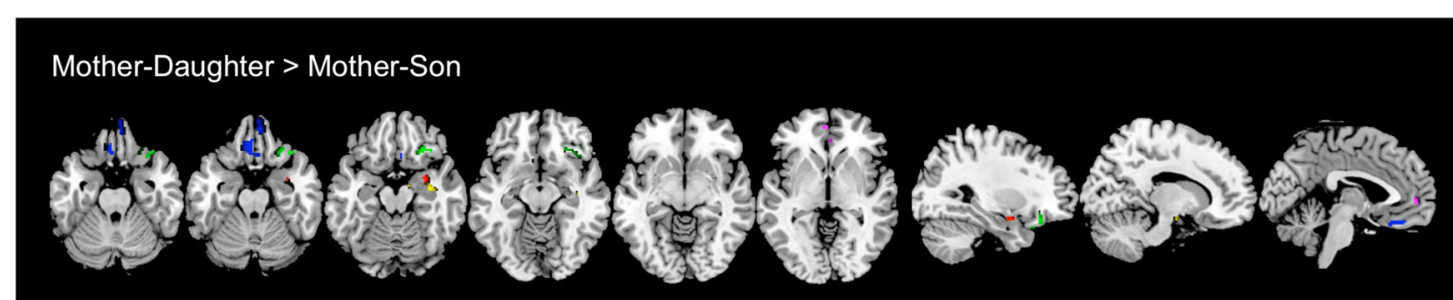

Mother-Daughter > Father-Daughter

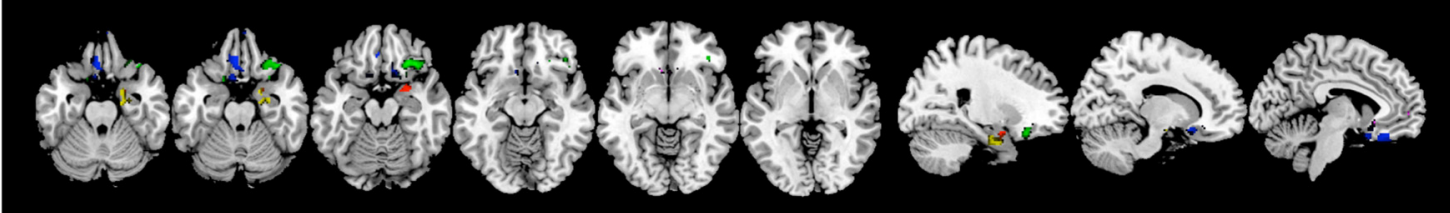

Mother-Daughter > Father-Son

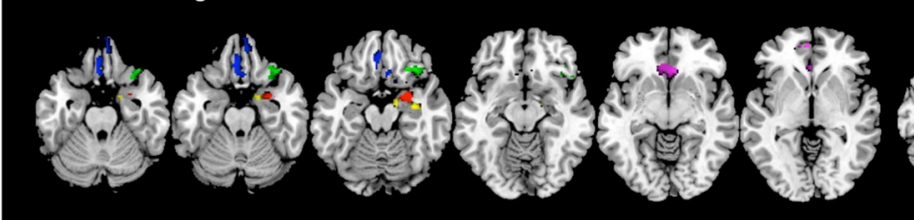

Lt
Rt

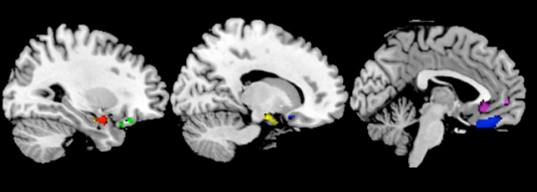

Rt

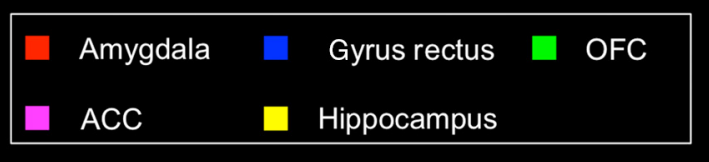

Figure 1. GMV associations between parents and offspring. Top, Brain regions showing significantly greater positive correlations in mother-daughter pairs compared with mother-son pairs. Middle, Brain regions showing significantly greater positive correlations in mother-daughter pairs compared with father- daughter pairs. Bottom, Brain regions showing significantly greater positive correlations in mother-daughter pairs compared with father-son pairs. All comparisons showed similar morphometric association patterns. Axial view of Talairach coordinates: $z,-27$, $-22,-17,-12,-7,-2$. Sagittal view of Talairach coordinates: $x, 29,13,-3$. Lt, Left; Rt, right. For all analyses, the statistical threshold is set at $p=0.05$ corrected.

$F_{(14,4)}=3.33, p=0.13$; Table 1$)$; hence, no post hoc analysis was performed. We performed voxelwise statistical comparisons of correlation coefficients between different parent-offspring pairs to find regions within the corticolimbic ROI in parent-offspring correlations were strongest for mother-daughter pairs. Analyses comparing mother-daughter versus mother-son, mother-daughter versus father-daughter, and mother-daughter versus father-son showed quite similar morphometric association patterns. Specifically, positive correlations between mothers and daughters were significantly greater than for other parent-offspring pairs in many of the corticolimbic structures, including the right amygdala, the bilateral ACC, vmPFC including the bilateral gyrus rectus (more prominent on the left) and bilateral OFC (more prominent on the right), and the right hippocampus and the bilateral parahippocampus gyrus (Fig. 1, Table 2). We also overlapped these brain maps to identify the brain areas that are most strongly correlated in motherdaughter relationships. Although the extent of brain regions became smaller (perhaps because of the conservative nature of conjoint analysis), we still observed significant voxels in the same brain areas (Fig. 2).

\section{Correlation between regional brain volume and behavioral data in daughters}

There was a positive correlation between GMV of the gyrus rectus and adaptability $T$ scores ( $r=0.710, p=0.021$ uncorrected); however, these results did not reach statistical significance when applying Bonferroni's correction. There was no significant correlation between GMV of the other brain regions and any behavioral measures despite other subscales showing similar or even greater variance (all $p$ values $>0.1$ corrected).

\section{Discussion}

The present study found female-specific intergenerational effects on brain structure between biological parent-offspring dyads. Specifically, consistent with our hypothesis, positive associations of regional GMV between mothers and daughters were significantly greater than mother-son, father-daughter, and fatherson associations in the amygdala, hippocampus, ACC, and vmPFC, which included the gyrus rectus and OFC. These findings may indicate that the daughter's corticolimbic circuitry is associated specifically with that of the mother's. A growing number of animal and human neuroimaging studies have implicated corticolimbic circuitry, specifically the amygdala, ACC, and vmPFC, as the biological substrates of emotion regulation. The amygdala regulates a variety of emotions, including depression, anxiety, and fear, and plays a major role in emotional memory processing and reactivity of the HPA axis to stress (Banks et al., 2007). The ventral ACC, in particular the pregenual and subgenual ACC, has functional connections with OFC, amygdala, and hippocampus and participates generally in emotion regulation (Drevets et al., 2008; Pizzagalli, 2011). The vmPFC, via its direct structural and functional connections with the amygdala (Ghashghaei et al., 2007), modulates emotional responses through GABAergic inhibitory projections (Akirav et al., 2006). Dysfunction in this circuitry is associated strongly with conditions such as mood and anxiety disorders (Price and Drevets, 2010). In addition, the finding in the hippocampus further supports our hypothesis. The hippocampus is one of the key components of emotional regulatory networks in the brain. Previous 
Table 2. Brain regions showing significantly greater positive correlations in mother- daughter pairs compared with other parent- offspring pairs

\begin{tabular}{|c|c|c|c|c|c|c|}
\hline \multirow[b]{2}{*}{ Brain region } & \multicolumn{3}{|c|}{$\begin{array}{l}\text { Montreal neurological } \\
\text { institute coordinates }\end{array}$} & \multirow[b]{2}{*}{$\mathrm{mm}^{3}$} & \multirow[b]{2}{*}{ zscore } & \multirow[b]{2}{*}{$p$} \\
\hline & $x$ & $y$ & $z$ & & & \\
\hline \multicolumn{7}{|l|}{ Mother-daughter } \\
\hline \multicolumn{7}{|l|}{$>$ mother-son } \\
\hline Right amygdala & 32 & -2 & -18 & 320 & 2.13 & 0.016 \\
\hline Right OFC & 30 & 27 & -18 & 1320 & 2.10 & 0.017 \\
\hline Bilateral gyrus rectus & -4 & 30 & -21 & 920 & 2.29 & 0.011 \\
\hline Right gyrus rectus & 7 & 52 & -23 & 944 & 3.19 & 0.001 \\
\hline Right ACC & 3 & 18 & -10 & 72 & 2.22 & 0.013 \\
\hline Left ACC & -2 & 52 & 1 & 232 & 2.46 & 0.006 \\
\hline Right hippocampus & 37 & -10 & -16 & 368 & 2.35 & 0.009 \\
\hline \multicolumn{7}{|l|}{ Mother- daughter } \\
\hline \multicolumn{7}{|l|}{$>$ father- daughter } \\
\hline Right amygdala & 24 & 2 & -20 & 360 & 1.88 & 0.030 \\
\hline Right OFC & 33 & 27 & -17 & 2032 & 3.37 & 0.001 \\
\hline Left OFC & -15 & 12 & -22 & 112 & 1.81 & 0.035 \\
\hline Bilateral gyrus rectus & -5 & 29 & -22 & 1048 & 2.93 & 0.001 \\
\hline Right gyrus rectus & 13 & 19 & -16 & 624 & 2.14 & 0.016 \\
\hline Left gyrus rectus & -8 & 14 & -19 & 616 & 1.98 & 0.023 \\
\hline Left ACC & -6 & 20 & -8 & 72 & 2.11 & 0.017 \\
\hline Right hippocampus & 22 & -6 & -25 & 1280 & 2.13 & 0.016 \\
\hline \multicolumn{7}{|l|}{ Mom-daughter } \\
\hline \multicolumn{7}{|l|}{$>$ father-son } \\
\hline Right amygdala & 26 & 0 & -19 & 832 & 2.28 & 0.011 \\
\hline Right OFC & 35 & 25 & -20 & 1456 & 3.23 & 0.001 \\
\hline Bilateral gyrus rectus & 0 & 30 & -21 & 1784 & 1.94 & 0.026 \\
\hline Right gyrus rectus & 7 & 51 & -23 & 736 & 2.93 & 0.001 \\
\hline Bilateral ACC & -1 & 27 & -7 & 1536 & 2.55 & 0.005 \\
\hline Right hippocampus & 24 & -6 & -18 & 944 & 1.71 & 0.043 \\
\hline Right parahippocampus & 20 & -12 & -28 & 256 & 2.39 & 0.008 \\
\hline
\end{tabular}

studies have reported that depression is associated with smaller hippocampal volume because of glucocorticoid neurotoxicity and stress-induced reduction in neurotrophic factors and neurogenesis (Sheline, 2011).

In this study, we show the intriguing finding that mother's and daughter's corticolimbic morphology was more similar than other parent-offspring pairs. Our study provides novel neurobiological support for female-specific transmission patterns in depression. Several previous studies have revealed that healthy controls with a family history of depression (high-risk group) compared with those with no family history of any psychiatric disease (low-risk group) had structural abnormalities in corticolimbic circuitry, including smaller hippocampus, smaller ACC, and larger amygdala volumes. They suggested that these structural anomalies may be potential neurobiological markers of vulnerability for depression (Boes et al., 2008; Chen et al., 2010; Romanczuk-Seiferth et al., 2014). Moreover, other data suggest that the combination of early-life adversity and smaller hippocampal size significantly increases the vulnerability for depression (Rao et al., 2010). Together, our findings indicate that, if mothers have brain structural anomalies in the corticolimbic circuitry, their female but not male offspring are more likely to have similar abnormal structural patterns in the same brain regions. Although additional research is warranted, these matrilineal associations may be tightly linked to greater vulnerability for daughters but not sons in developing depression when their mothers have depression.

It is currently difficult to point to the precise underlying mechanisms of our findings because of lack of previous studies. Nonetheless, one may speculate that genetic, prenatal, and postnatal environmental factors and their interactions may underlie female-specific intergenerational patterns in depression symptoms, brain morphometry, and gene expression patterns in the corticolimbic circuitry. In addition to animal studies mentioned in the Introduction, gestational stress leads to increased corticotropin releasing hormone mRNA in the amygdala (Cratty et al., 1995), and the amount of maternal care influences epigenetic modification (methylation) to hypothalamic estrogen receptor $\alpha$ in female rats (Champagne et al., 2006). These studies provide the underlying neurobiological evidence of female-specific intergenerational effects by examining gene expression in brain tissue. Furthermore, female but not male offspring of mice show a reduction in hippocampal glial count in the pyramidal layer after prenatal stress (Behan et al., 2011). In humans, one multisite survey in both genetically related and unrelated parent-offspring pairs reported that girls may be more prone to the negative influences of maternal depression symptoms than boys through environmental processes (Lewis et al., 2011). A previous study revealed that higher maternal prenatal cortisol level and offspring's depression problems were associated with larger right amygdala volumes in girls but not boys (Buss et al., 2012). These findings indicate the presence of female-specific placental adaptation to stress exposure (Clifton, 2010), which may influence more similar neurodevelopmental trajectory among females compared with males in the corticolimbic circuitry. Longitudinal studies in families with different genetic, prenatal, and postnatal environmental influences are needed to examine the relationship between maternal stress, endocrine effects, and brain development in mothers and their daughters.

Furthermore, in the gyrus rectus, which is the medial part of the OFC, a positive correlation between GMV of daughters and their adaptability in the BASC-2 was found, such that larger volumes of the OFC may be related to higher levels of adaptability. This finding may support previous animal studies indicating that the OFC contributes to emotional and social adaptive behavior (Roberts, 2006). Behavioral measures in the current study were collected for the broader purpose of another study and were not optimized to examine intergenerational effects; hence, together with the small sample and lack of measures in parents, the results of this exploratory analysis should be interpreted with caution.

There has been increasing consensus on sex differences in gray matter developmental trajectories (Giedd et al., 1999; De Bellis et al., 2001). Cerebral volume and GMV in the frontal and parietal lobes peak earlier in girls than in boys (Lenroot and Giedd, 2006). Moreover, sex differences have been demonstrated in the hippocampus (larger in females), amygdala (larger in males), and thalamus (larger in males; Koolschijn and Crone, 2013); however, our study found that mother-daughter pairs consistently demonstrated significantly greater positive GMV correlations compared with the other parent-offspring pairs not only in the amygdala and medial PFC in which volume is larger in males than in females but also in the OFC and hippocampus in which volume is larger in females than in males (Cosgrove et al., 2007; Koolschijn and Crone, 2013). These results indicate that sex difference in these brain volumes cannot account for the pattern of associations we observed. Additional research is needed to examine the mechanisms underlying the consistent female-specific association patterns in each brain region showing a pronounced sexual dimorphism in development within the corticolimbic circuitry.

Several limitations of this study should be noted. First, because we only used genetically related families, in which genetic, prenatal, and postnatal environments are shared and did not include in vitro fertilization (IVF) and adoptive families, we were 


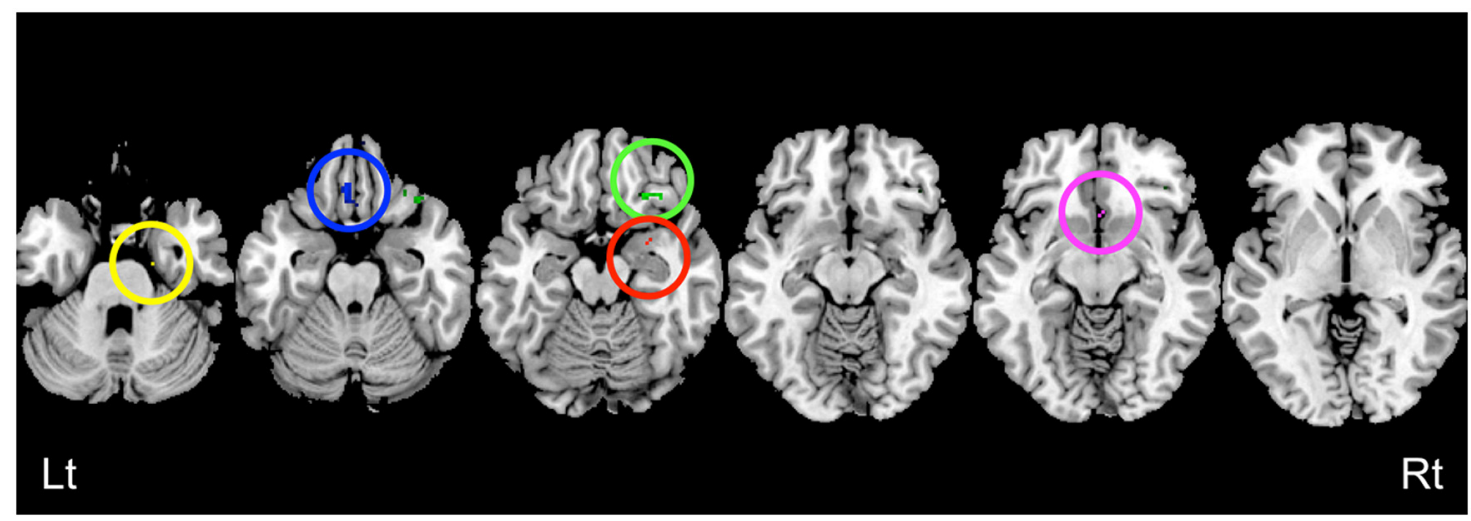

Figure 2. Brain areas specific to mother-daughter relationships. Brain map representing voxels that overlap between three maps presented in Figure 1 to illustrate a specific positive association in mother- daughter pairs. Red circle represents amygdala. Blue circle represents the gyrus rectus. Green circle represents the OFC. Pink circle represents the ACC. Yellow circle represents the parahippocampus gyrus. Although the extent of brain regions are smaller compared with Figure 1 (because of the conservative nature of conjoint analysis), we still observed significant voxels in the same brain areas. Lt, Left; Rt, right. For all analyses, the statistical threshold is set at $p=0.05$ corrected.

unable to dissociate the influence of these three factors on our neurobiological findings of intergenerational effects. Second, we did not directly examine how functional and anatomical connectivities within corticolimbic circuitry are mediated by the intergenerational effects in this sample. Therefore, additional studies using multimodal imaging in three different groups (genetic, IVF, and adoptive groups) are needed. Third, we only focused on matrilineal transmission patterns in the human brain based on our hypothesis; however, Rodgers et al. $(2013,2015)$ found that stressed male mice show an increase in micro-RNAs in their sperm, leading to reduced HPA stress axis responsivity in adult offspring. The result indicates novel epigenetic mechanisms of paternal transmission patterns in neuropsychiatric disorders including depression. Thus, it is also important to examine paternal intergenerational transmission effects in the corticolimbic circuitry in future studies. Fourth, the human amygdala appears to undergo rapid development early in life (Tottenham et al., 2009). Amygdala structural growth is complete by 4 years old (Giedd et al., 1996), and functional development reaches its peak during adolescence (Hare et al., 2008). Conversely, in rodent models, the vmPFC develops late in life (Van Eden and Uylings, 1985) and connectivity between the amygdala and the vmPFC does not emerge until adolescence (Cunningham et al., 2002). Therefore, longitudinal studies are required to explore how our findings of female-specific intergenerational patterns are affected by the developmental trajectory in the corticolimbic circuitry. In the current study, although cross-sectional, we attempted to capture children with minimal influence of puberty and extra-family environment on the brain (Dahl, 2004). Finally, because of the relatively small sample size and exploratory nature of our analysis, the current findings are preliminary and require additional research with a larger sample. However, the current study represents the first study to examine parental transmission patterns of corticolimbic morphometry in humans in vivo.

In summary, to our knowledge, this is the first study to investigate intergenerational transmission patterns in the human brain using neuroimaging. We demonstrate a significant matrilineal association between parents and their offspring in a brain circuit associated with emotion regulation as measured by regional GMV. Our results provide new insights into the potential neuroanatomical basis of female-specific intergenerational effects of psychiatric conditions, especially in depression. Findings from our study have the potential to bridge animal work and clinical observations. Ultimately, findings such as ours may have important implications for furthering the understanding and the creation of developmental stage-specific and circuit-based treatment intervention of mental illnesses, such as depression, that show intergenerational effects.

\section{References}

Akirav I, Raizel H, Maroun M (2006) Enhancement of conditioned fear extinction by infusion of the GABA(A) agonist muscimol into the rat prefrontal cortex and amygdala. Eur J Neurosci 23:758-764. CrossRef Medline

Alemany S, Mas A, Goldberg X, Falcón C, Fatjó-Vilas M, Arias B, Bargalló N, Nenadic I, Gastó C, Fañanás L (2013) Regional gray matter reductions are associated with genetic liability for anxiety and depression: an MRI twin study. J Affect Disord 149:175-181. CrossRef Medline

Ashburner J (2007) A fast diffeomorphic image registration algorithm. Neuroimage 38:95-113. CrossRef Medline

Banks SJ, Eddy KT, Angstadt M, Nathan PJ, Phan KL (2007) Amygdalafrontal connectivity during emotion regulation. Soc Cogn Affect Neurosci 2:303-312. CrossRef Medline

Beardslee R, Versage M, Gladstone R (1998) Children of affectively ill parents: a review of the past 10 years. J Am Acad Child Adolesc Psychiatry 34:1134-1141.

Behan AT, van den Hove DL, Mueller L, Jetten MJ, Steinbusch HW, Cotter DR, Prickaerts J (2011) Evidence of female-specific glial deficits in the hippocampus in a mouse model of prenatal stress. Eur Neuropsychopharmacol 21:71-79. CrossRef Medline

Boes AD, McCormick LM, Coryell WH, Nopoulos P (2008) Rostral anterior cingulate cortex volume correlates with depressed mood in normal healthy children. Biol Psychiatry 63:391-397. CrossRef Medline

Buss C, Davis EP, Shahbaba B, Pruessner JC, Head K, Sandman CA (2012) Maternal cortisol over the course of pregnancy and subsequent child amygdala and hippocampus volumes and affective problems. Proc Natl Acad Sci U S A 109:E1312-E1319. CrossRef Medline

Cabrera NJ, Fagan J, Wight V, Schadler C (2011) Influence of mother, father, and child risk on parenting and children's cognitive and social behaviors. Child Dev 82:1985-2005. CrossRef Medline

Casanova R, Srikanth R, Baer A, Laurienti PJ, Burdette JH, Hayasaka S, Flowers L, Wood F, Maldjian JA (2007) Biological parametric mapping: a statistical toolbox for multimodality brain image analysis. Neuroimage 34:137-143. CrossRef Medline

Champagne FA, Weaver IC, Diorio J, Dymov S, Szyf M, Meaney MJ (2006) Maternal care associated with methylation of the estrogen receptoralphalb promoter and estrogen receptor-alpha expression in the medial preoptic area of female offspring. Endocrinology 147:2909-2915. CrossRef Medline

Chen MC, Hamilton JP, Gotlib IH (2010) Decreased hippocampal volume in healthy girls at risk of depression. Arch Gen Psychiatry 67:270-276. CrossRef Medline 
Clifton VL (2010) Review: Sex and the human placenta: mediating differential strategies of fetal growth and survival. Placenta 31 [Suppl]:S33-S39. CrossRef

Cosgrove KP, Mazure CM, Staley JK (2007) Evolving knowledge of sex differences in brain structure, function, and chemistry. Biol Psychiatry 62: 847-855. CrossRef Medline

Cratty MS, Ward HE, Johnson EA, Azzaro AJ, Birkle DL (1995) Prenatal stress increases corticotropin-releasing factor (CRF) content and release in rat amygdala minces. Brain Res 675:297-302. CrossRef Medline

Cunningham MG, Bhattacharyya S, Benes FM (2002) Amygdalo-cortical sprouting continues into early adulthood: implications for the development of normal and abnormal function during adolescence. J Comp Neurol 453:116-130. CrossRef Medline

Curley JP (2011) Is there a genomically imprinted social brain?. Bioessays 33:662-668. CrossRef Medline

Curley JP, Mashoodh R (2010) Parent-of-origin and trans-generational germline influences on behavioral development: the interacting roles of mothers, fathers, and grandparents. Dev Psychobiol 52:312-330. CrossRef Medline

Dahl RE (2004) Adolescent brain development: a period of vulnerabilities and opportunities. Keynote address. Ann N Y Acad Sci 1021:1-22. CrossRef

Davies PT, Windle M (1997) Gender-specific pathways between maternal depressive symptoms, family discord, and adolescent adjustment. Dev Psychol 33:657-668. CrossRef Medline

De Bellis MD, Keshavan MS, Beers SR, Hall J, Frustaci K, Masalehdan A, Noll J, Boring AM (2001) Sex differences in brain maturation during childhood and adolescence. Cereb Cortex 11:552-557. CrossRef Medline

Downey G, Coyne JC (1990) Children of depressed parents: an integrative review. Psychol Bull 108:50-76. CrossRef Medline

Drevets WC, Savitz J, Trimble M (2008) The subgenual anterior cingulate cortex in mood disorders. CNS Spectr 13:663-681. Medline

Efron B, Tibshirani J (1993) An introduction to the bootstrap. London: Chapman and Hall.

Fergusson DM, Horwood LJ, Lynskey MT (1995) Maternal depressive symptoms and depressive symptoms in adolescents. J Child Psychol Psychiatry 36:1161-1178. CrossRef Medline

Ghashghaei HT, Hilgetag CC, Barbas H (2007) Sequence of information processing for emotions based on the anatomic dialogue between prefrontal cortex and amygdala. Neuroimage 34:905-923. CrossRef Medline

Giedd JN, Vaituzis AC, Hamburger SD, Lange N, Rajapakse JC, Kaysen D, Vauss YC, Rapoport JL (1996) Quantitative MRI of the temporal lobe, amygdala, and hippocampus in normal human development: ages 4-18 years. J Comp Neurol 366:223-230. CrossRef Medline

Giedd JN, Blumenthal J, Jeffries NO, Castellanos FX, Liu H, Zijdenbos A, Paus T, Evans AC, Rapoport JL (1999) Brain development during childhood and adolescence: a longitudinal MRI study. Nat Neurosci 2:861-863. CrossRef Medline

Goodman SH (2007) Depression in mothers. Annu Rev Clin Psychol 3: 107-135. CrossRef Medline

Goodman SH, Gotlib IH (1999) Risk for psychopathology in the children of depressed mothers: a developmental model for understanding mechanisms of transmission. Psychol Rev 106:458-490. CrossRef Medline

Guilmatre A, Sharp AJ (2012) Parent of origin effects. Clin Genet 81: 201-209. CrossRef Medline

Hare TA, Tottenham N, Galvan A, Voss HU, Glover GH, Casey BJ (2008) Biological substrates of emotional reactivity and regulation in adolescence during an emotional go-nogo task. Biol Psychiatry 63:927-934. CrossRef Medline

Hoeft F, Lightbody AA, Hazlett HC, Patnaik S, Piven J, Reiss AL (2008) Morphometric spatial patterns differentiating boys with fragile X syndrome, typically developing boys, and developmentally delayed boys aged 1 to 3 years. Arch Gen Psychiatry 65:1087-1097. CrossRef Medline

Hoeft F, Walter E, Lightbody AA, Hazlett HC, Chang C, Piven J, Reiss AL (2011) Neuroanatomical differences in toddler boys with fragile X syndrome and idiopathic autism. Arch Gen Psychiatry 68:295-305. CrossRef Medline

Koolschijn PC, Crone EA (2013) Sex differences and structural brain maturation from childhood to early adulthood. Dev Cogn Neurosci 5: 106-118. CrossRef Medline

Lancaster JL, Woldorff MG, Parsons LM, Liotti M, Freitas CS, Rainey L, Kochunov PV, Nickerson D, Mikiten SA, Fox PT (2000) Automated
Talairach atlas labels for functional brain mapping. Hum Brain Mapp 10:120-131. CrossRef Medline

Lenroot RK, Giedd JN (2006) Brain development in children and adolescents: insights from anatomical magnetic resonance imaging. Neurosci Biobehav Rev 30:718-729. CrossRef Medline

Lewis G, Rice F, Harold GT, Collishaw S, Thapar A (2011) Investigating environmental links between parent depression and child depressive/anxiety symptoms using an assisted conception design. J Am Acad Child Adolesc Psychiatry 50:451-459.e1. CrossRef Medline

Montano MM, Wang MH, vom Saal FS (1993) Sex differences in plasma corticosterone in mouse fetuses are mediated by differential placental transport from the mother and eliminated by maternal adrenalectomy or stress. J Reprod Fertil 99:283-290. CrossRef Medline

Piche G, Bergeron L, Cyr M, Berthiaume C (2011) Maternal lifetime depressive/anxiety disorders and children's internalizing symptoms: the importance of family context. J Can Acad Child Adolesc Psychiatry 20:176-185. Medline

Pizzagalli DA (2011) Frontocingulate dysfunction in depression: toward biomarkers of treatment response. Neuropsychopharmacology 36 : 183-206. CrossRef Medline

Pletzer B, Kronbichler M, Aichhorn M, Bergmann J, Ladurner G, Kerschbaum HH (2010) Menstrual cycle and hormonal contraceptive use modulate human brain structure. Brain Res 1348:55-62. CrossRef Medline

Price JL, Drevets WC (2010) Neurocircuitry of mood disorders. Neuropsychopharmacology 35:192-216. CrossRef Medline

R Core Team (2015) R: a language and environment for statistical computing. Vienna: R Foundation for Statistical Computing.

Rao U, Chen LA, Bidesi AS, Shad MU, Thomas MA, Hammen CL (2010) Hippocampal changes associated with early-life adversity and vulnerability to depression. Biol Psychiatry 67:357-364. CrossRef Medline

Reynolds R, Kamphaus W (2004) BASC-2: behavior assessment system for children, Ed 2 manual. San Antonio, TX: Pearson.

Roberts AC (2006) Primate orbitofrontal cortex and adaptive behaviour. Trends Cogn Sci 10:83-90. CrossRef Medline

Rodgers AB, Morgan CP, Bronson SL, Revello S, Bale TL (2013) Paternal stress exposure alters sperm microRNA content and reprograms offspring HPA stress axis regulation. J Neurosci 33:9003-9012. CrossRef Medline

Rodgers AB, Morgan CP, Leu NA, Bale TL (2015) Transgenerational epigenetic programming via sperm microRNA recapitulates effects of paternal stress. Proc Natl Acad Sci U S A 112:13699-13704. CrossRef Medline

Romanczuk-Seiferth N, Pöhland L, Mohnke S, Garbusow M, Erk S, Haddad L, Grimm O, Tost H, Meyer-Lindenberg A, Walter H, Wüstenberg T, Heinz A (2014) Larger amygdala volume in first-degree relatives of patients with major depression. Neuroimage Clin 5:62-68. CrossRef Medline

Sheline YI (2011) Depression and the hippocampus: cause or effect?. Biol Psychiatry 70:308-309. CrossRef Medline

Szuran TF, Pliska V, Pokorny J, Welzl H (2000) Prenatal stress in rats: effects on plasma corticosterone, hippocampal glucocorticoid receptors, and maze performance. Physiol Behav 71:353-362. CrossRef Medline

Thompson SM, Hammen C, Starr LR, Najman JM (2014) Oxytocin receptor gene polymorphism (rs53576) moderates the intergenerational transmission of depression. Psychoneuroendocrinology 43:11-19. CrossRef Medline

Tottenham N, Hare TA, Casey BJ (2009) A developmental perspective on human amygdala function. In: The human amygdala (Phelps E, Whalen P, eds), pp 107-117. New York: Guilford.

Van Eden CG, Uylings HB (1985) Postnatal volumetric development of the prefrontal cortex in the rat. J Comp Neurol 241:268-274. CrossRef Medline

Weinstock M, Matlina E, Maor GI, Rosen H, McEwen BS (1992) Prenatal stress selectively alters the reactivity of the hypothalamic-pituitary adrenal system in the female rat. Brain Res 595:195-200. CrossRef Medline

Weissman MM, Wickramaratne P, Nomura Y, Warner V, Pilowsky D, Verdeli H (2006) Offspring of depressed parents: 20 years later. Am J Psychiatry 163:1001-1008. CrossRef Medline

Zhu Z, Li X, Chen W, Zhao Y, Li H, Qing C, Jia N, Bai Z, Liu J (2004) Prenatal stress causes gender-dependent neuronal loss and oxidative stress in rat hippocampus. J Neurosci Res 78:837-844. CrossRef Medline 